\title{
LOS REINOS PERDIDOS. ARQUEOLOGÍA DEL ESTADO EN EL CUERNO DE ÁFRICA
}

\section{THE LOST KINGDOMS. ARCHAEOLOGY OF THE STATE IN THE HORN OF AFRICA}

\author{
Alfredo González-Ruibal ${ }^{1}$ \\ Recibido: 25/10/2021 - Aceptado: 11/12/2021 \\ DOI: https://doi.org/10.5944/etfi.14.2021.32055
}

\section{Resumen}

El Cuerno de África fue la cuna de los estados más antiguos del África Subsahariana, pero son escasamente conocidos y raramente se tienen en cuenta en discusiones generales sobre el origen de las sociedades jerarquizadas y las formaciones estatales. Sin embargo, durante tres milenios, el Cuerno fue testigo de la emergencia, desarrollo y colapso de diferentes organizaciones estatales, las cuales con frecuencia contradicen nuestras concepciones de lo que es un estado. Tienen mucho en común con otros estados africanos, como sus tendencias heterárquicas o la importancia de los símbolos materiales, los mitos y el ritual. En este artículo paso revista a los diferentes modelos de estado que se pueden identificar en el Cuerno de África desde una perspectiva arqueológica. Se advierten varios rasgos generales, como el carácter fragmentario y heterogéneo de su territorio, las fronteras porosas, la persistencia de comunidades no asimiladas en el interior del estado o la tendencia a la fisión y el colapso, que se relaciona con una fricción permanente entre fuerzas centrípetas y centrífugas.

\section{Palabras clave}

Etiopía; Somalia; Sudá; formación del estado; colapso estatal; resistencia social.

\section{Abstract}

The Horn of Africa was the cradle of the earliest states in Subsaharan Africa, but they are scarcely known and rarely considered in general discussions on the origin of hierarchical societies and state formations. Yet for some three millennia the Horn saw the emergence, development and collapse of different state organizations which often contradict our conceptions of what a state is. They have much in common with other African states, such as their heterarchical tendencies or the relevance of material symbols, myth and ritual. In this paper a review of the different state models that can be identified in the Horn of Africa is provided from

1. Incipit-CSIC, alfredo.gonzalez-ruibal@incipit.csic.es 
an archaeological perspective. Some shared features can be observed, such as the fragmentary, heterogeneous nature of their territory, their porous borderlands and the persistence of non-assimilated communities within the territory of the polity and the tendency to fission and collpase, which is related to a friction between centripetal and centrifugal forces always at play.

\section{Keywords}

Ethiopia; Somalia; Sudan; state formation; state collapse; social resistance. 


\section{INTRODUCCIÓN. ARQUEOLOGÍAS DEL ESTADO}

La emergencia de los estados es uno de los grandes temas de la arqueología -para una revisión de teorías y casos véase Trigger (2003), Lull y Micó (2007). El estudio se ha centrado, sin embargo, prioritariamente en los núcleos de emergencia primaria del estado: el valle del Nilo, el Próximo Oriente, los Andes y Mesoamérica. Por otro lado, los conceptos de estado que manejamos están, inevitablemente, teñidos de nuestra propia experiencia: todos los arqueólogos (y antropólogos) vivimos en sociedades estatales. Como señalan David Graeber y David Wengrow (202I), esto significa que en buena medida hemos proyectado un modelo muy específico de estado, que solo se desarrolla a partir del siglo XIX, a otras épocas de la historia. Ese estado se caracteriza por una combinación específica de liderazgo carismático, violencia y administración. Estas tres formas elementales de dominación no se dan en todos los estados que conocemos y desde luego no entre las primeras formaciones políticas que se identifican como tales, donde lo más habitual es que aparezcan una o dos formas de dominación. La manera concreta que adopta además la articulación de política carismática, monopolio de la violencia y burocracia en época contemporánea es realmente única en la historia de la humanidad y no sirve de referencia para entender otras organizaciones sociopolíticas -más bien lo contrario. Graeber y Wengrow ofrecen buenos argumentos para abandonar el concepto de estado por completo y utilizar en cambio los términos que con más frecuencia aparecen en los textos antiguos y la etnografía: reinos o jefaturas.

En este artículo retendré el concepto de estado en un sentido específico: siguiendo a Pierre Clastres (200I), defiendo que el estado es la manifestación de un orden social dividido, pero también la forma en que se organiza esa división social. Desde este punto de vista, la diferencia fundamental se da entre sociedades con o sin estado -con o sin división social. Así pues, incluiré en el concepto de estado formaciones políticas jerarquizadas, con líderes que pueden ejercer poder efectivo sobre sus súbditos, independientemente de que dichas formaciones políticas lleguen a desarrollar elementos que habitualmente asociamos con el estado, como puede ser la escritura, la administración, una clase sacerdotal o un ejército. Evito, sin embargo, el concepto habitual en arqueología de «sociedades complejas» (e.g. Stein 1998), que por ser más vago podría encajar mejor en esta concepción de estado, porque presupone que las sociedades sin estado (sin división social) no pueden ser complejas, lo cual es un error.

Una buena manera de pensar el estado de otra manera es explorar regiones y períodos que han quedado fuera de la discusión habitual sobre este tema. El África Subsahariana, por ejemplo, nos ofrece modelos de organización sociopolítica alternativos que son, sin embargo, poco conocidos fuera del continente y apenas se tienen en consideración en los debates sobre sociedades jerarquizadas (McKintosh I999). Por lo que se refiere a los estados, muchas veces carecen de elementos que se consideran definitorios, como la escritura o el control territorial. En su trabajo pionero sobre organización política en África, Meyer Fortes y Evans-Pritchard (2015 [1940]) identifican una serie de rasgos característicos en varias sociedades africanas jerarquizadas, entre los cuales se encuentran la limitación del poder 
del monarca, su importante función ritual, la idea del monarca como garante de la fertilidad, el orden del cosmos y la reproducción social, el equilibrio de poder entre distintos colectivos, la representatividad y el papel central que desempeñan los símbolos en la cohesión social dentro del estado. Southall (I988) desarrolló el concepto de «estado segmentario» para definir muchas de estas organizaciones sociopolíticas que comparten rasgos con sociedades tribales, como es la importancia de la acción colectiva, los linajes y la existencia de múltiples jefes que restringen la capacidad de acción del líder supremo. El propio cuerpo del monarca tiene una conceptualización muy distinta al de otros estados: existe en muchos casos la idea de que debe protegerse contra diversas fuentes de polución simbólica o física, puesto que la capacidad del rey de dar la vida y promover la fertilidad depende de su cuerpo y los fluidos corporales (Warnier, 2007), de ahí, también la costumbre del asesinato del rey: cuando este pierde vigor y ya no puede garantizar la vida, la solución es acabar con él y poner a otro en su lugar. En ciertas sociedades esta costumbre se sustituyó por el sacrificio de un perro (Evans-Pritchard, 2014 [I948]).

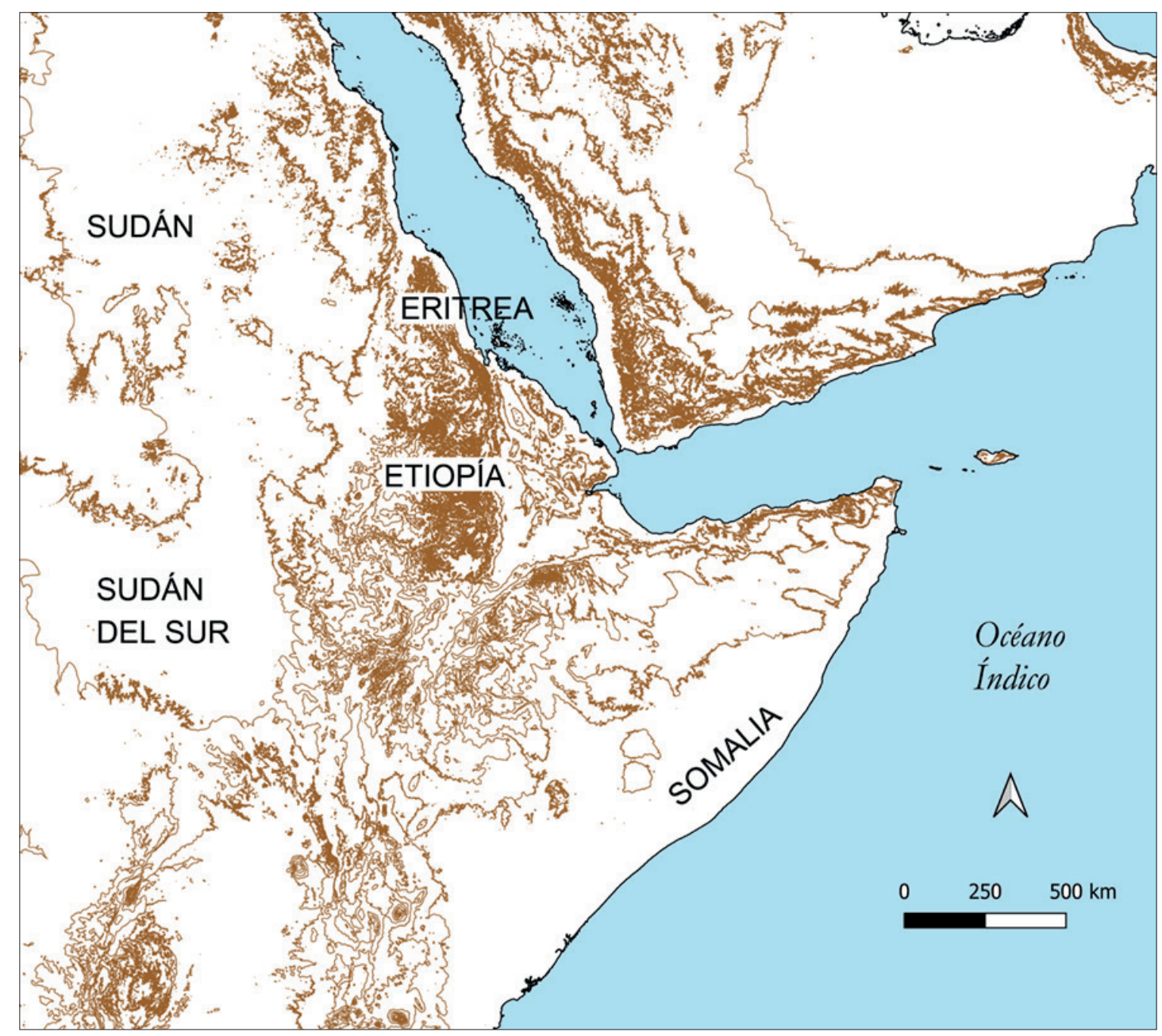

FIGURA 1. MAPA DEL CUERNO DE ÁFRICA. SE APRECIA EL MACIZO MONTAÑOSO QUE OCUPA EL CENTRO DE ETIOPÍA Y ERITREA, DONDE SE DESARROLLARON LA MAYOR PARTE DE LOS ESTADOS. Mapa del autor 
En este artículo analizaré la región al sur del Sáhara donde se desarrollaron las primeras formaciones estatales -el Cuerno de África (Figura I) - y pasaré revista a algunas de las principales formaciones estatales que se desarrollaron allí (Tabla I). El Cuerno es al mismo tiempo una de las zonas donde más han perdurado las sociedades segmentarias, lo cual ha dado lugar a un intrincado mosaico de etnias, sociedades, estados y fronteras a lo largo de tres mil años. La geografía desempeñó un papel no menor en este proceso histórico: conviene tener en cuenta que el Cuerno está dominado por un altiplano que ocupa casi un millón de kilómetros cuadrados en la parte central de la región y que se sitúa en alturas comprendidas entre los I.700 y los 4.550 metros de altura. El altiplano está delimitado por escarpes, frecuentemente abruptos, que caen varios cientos de metros hacia las tierras bajas, situadas entre los 400 y los 800 metros y que rodean por completo el macizo montañoso. Mientras que el altiplano posee un clima templado y lluvioso, las tierras bajas son tórridas y el paisaje comprende desiertos y estepas (como en Yibuti y Somalia) y sabanas y bosque tropical seco (en el este). Las formaciones estatales y de carácter jerarquizado se desarrollaron en el altiplano, mientras que en las tierras bajas han pervivido hasta la actualidad sociedades segmentarias compuestas por cazadores-recolectores, pastores nómadas y agricultores de roza.

\begin{tabular}{|l|l|l|}
\hline ESTADO & LOCALIZACIÓN & CRONOLOGíA \\
\hline D'MT & $\begin{array}{l}\text { Eritrea-Norte de Etiopía, } \\
\text { Somalilandia, Puntlandia }\end{array}$ & s. VIII-IV a.C. \\
\hline Axum & Eritrea-Norte de Etiopía & s. I-VIII d.C. \\
\hline Reino cristiano de Etiopía & Altiplano norte de Etiopía & s. XIII-s. XIX d.C. \\
\hline Sultanatos islámicos & $\begin{array}{l}\text { Este de Etiopía, Somalilandia, } \\
\text { Puntlandia, Yibuti }\end{array}$ & s. XIII-s. XVI d.C. \\
\hline Reinos omóticos & Altiplano sur de Etiopía & s. XIII-s. XIX d.C. \\
\hline Estados de frontera & Frontera etíope-sudanesa & s. XVIII-s. XX d.C. \\
\hline
\end{tabular}

TABLA 1. PRINCIPALES ESTADOS MENCIONADOS EN EL TEXTO.

\section{ESTADOS FORASTEROS Y SOCIEDADES SIN ESTADO EN EL I MILENIO A.C.}

El origen de las formaciones estatales en el Cuerno de África parece un ejemplo paradigmático de emergencia secundaria del estado: en torno al 800 a.C. surgen en determinados puntos del norte del altiplano etíope-eritreo elementos culturales característicos de la sociedad sabea del sur de Arabia (Fattovich, 1990; Fattovich, 2010: 157). Se trata de templos de sillería dedicados a divinidades sudarábigas, como Almaqah (la luna), altares y tronos de piedra, estatuas, frisos s e inscripciones monumentales en escritura y lengua sabea, todo ello con paralelos iconográficos, tipológicos, teonímicos y patronímicos claros en el actual Yemen (Wolf y Nowotnick, 20Io; Japp et al., 20II). No es sorprendente que en un principio se entendiera la presencia de estos elementos 
como prueba de una colonización sabea del norte del Cuerno de África entre los siglos VIIl y IV a.C., que habría dado pie a un reino de origen sudarábigo. De hecho, varias inscripciones mencionan un reino conocido como D'MT y varios nombres de reyes han quedado registrados. No obstante, la investigación arqueológica desde finales de los años 90 ha demostrado que la situación es bastante más complicada de lo que se pensaba. Para empezar, no existe un continuum de esos elementos claramente sabeos que definan un territorio homogéneo. Parecen más bien islas en un entorno altamente diverso (Fattovich, 2009). De hecho, en tiempos recientes se han descubierto evidencias sabeas también en la costa somalí (Schiettecatte et al., 202I), nuevamente sin que formen parte de un complejo cultural territorialmente extenso y homogéneo. El caso más llamativo es el de Puntlandia (Somalia): en la zona de Ras Hafun, cerca del cabo Guardafui que forma la punta del Cuerno de África, se ha localizado de forma fortuita un colosal templo de sillería con inscripciones monumentales, fechado con criterios paleográficos a fines del siglo VIII, inicios del VIl a.C. El templo, dedicada a la divinidad Akhakhatán, fue levantado por orden del almirante de la flota del reino sabeo con capital en Márib, en las montañas del centro de Yemen, y su función debió de ser, seguramente, controlar un punto clave en el comercio del incienso, que desempeñó un papel muy importante en la economía sudarábiga. El templo de Ras Hafun no debía de ser muy diferente, en cuanto a su naturaleza, a los que se levantaron en el altiplano etíope, entre los cuales el más famoso es el de Yeha (Fattovich, 2009) (Figura 2). Se trata de espacios simbólicamente muy poderosos, pero también aislados, en un entorno en el que predominaba con mucho el elemento indígena, ahora mejor conocido gracias a las prospecciones arqueológicas sistemáticas del territorio (Michels, 2005).

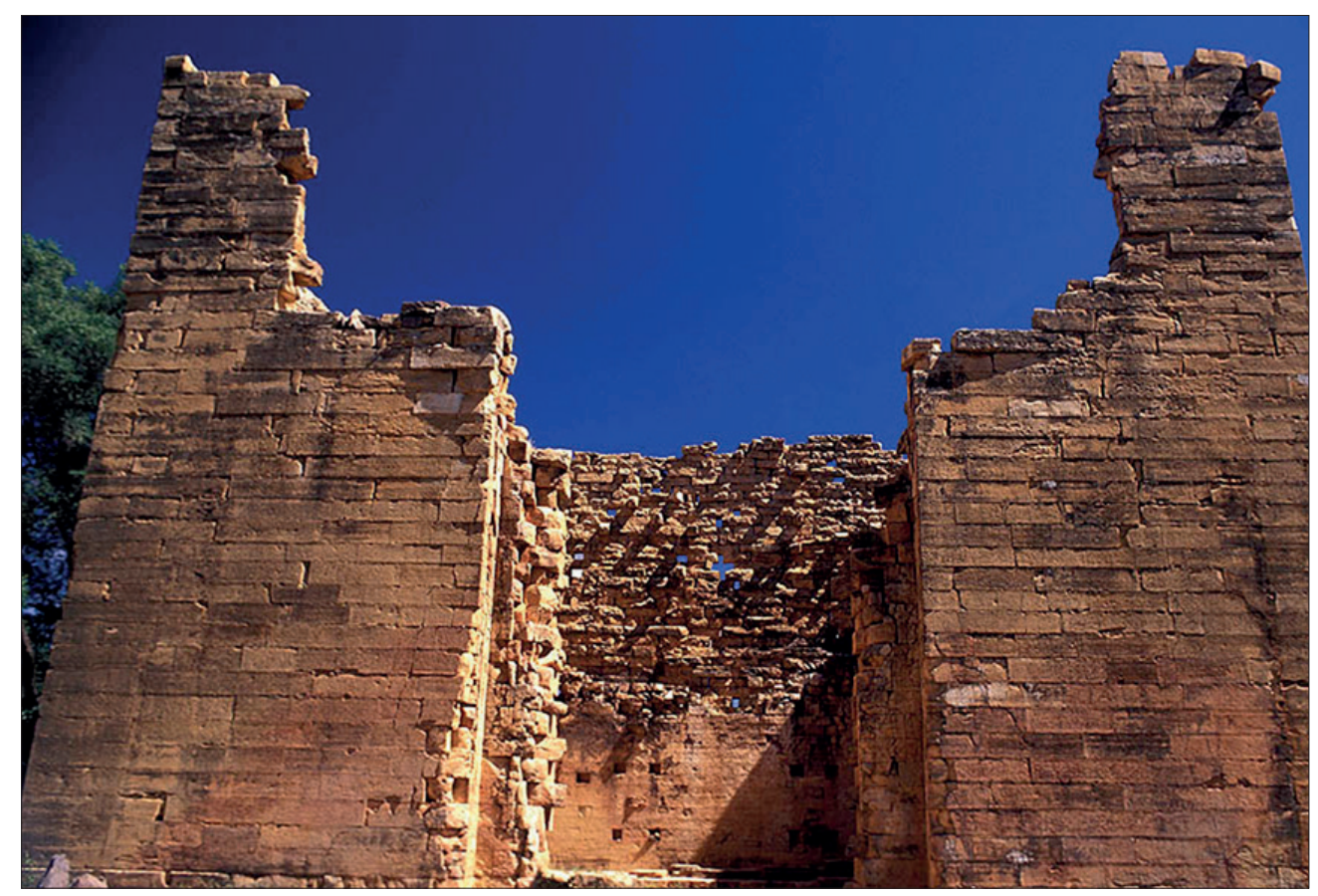

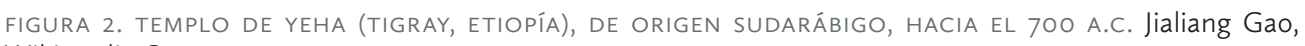
Wikimedia Commons 
En las prospecciones llevadas a cabo en la región de Asmara (Eritrea) se documentó una potente tradición local, denominada por sus descubridores Antigua Ona, que surge de manera autónoma a inicios del I milenio a.C. y coincide cronológicamente, por tanto, con la tradición sabea documentada algo más al sur (Schmidt y Curtis, 20oI; Curtis, 2009). Pese a la enorme explosión demográfica que supone la aparición de esta cultura, de la que se han registrado centenares de yacimientos, y la jerarquización de asentamientos (algunos de decenas de hectáreas), todo indica que la organización social era notablemente igualitaria desde un punto de vista socioeconómico, pues no se ha documentado una cultura material de elite ni diferencias sociales en la arquitectura o los enterramientos -solo hacia el final del período parecen surgir tumbas de elite. Así pues, durante el I milenio a.C. en el norte del Cuerno de África no tenemos un estado territorial de origen sabeo o una colonia sabea con un dominio amplio del territorio, sino un mosaico étnico, cultural y político en el que conviven, en el mismo espacios, formas de organización y de cultura material muy distintas e incluso contrapuestas. De hecho, debían existir grupos humanos diversos, también racialmente, porque los testimonios epigráficos hablan de gente «roja»y «negra» (Fattovich, 2010: 157), una división que perdura en ciertas zonas de Etiopía hasta la actualidad (los «rojos» suelen ser los semíticos y en general los habitantes del altiplano, los «negros», los nilosaharianos). Así, mientras en la costa somalí los establecimientos sabeos convivían con comunidades nómadas, en el caso del altiplano etíope y eritreo lo hacían con sociedades agropastoriles sedentarias que vivían en poblados permanentes, a veces de gran tamaño, con arquitectura de piedra. Es posiblemente en esta época cuando se introduce la agricultura del arado, un fenómeno único en la región subsahariana (McCann, I995).

Hacia el 400 a.C. comienza a emerger una tradición local en el altiplano que es producto de la mezcla entre la tradición sabea y la local y que es todavía poco conocida: en Axum, la que será capital del futuro reino del mismo nombre, se ha documentado un gran asentamiento de esta época con su espacio funerario asociado, de cerca de io hectáreas, y un poblamiento regional jerarquizado en su entorno (Bard et al., 1997). De aquí surgirá, desde fines del siglo I a.C., el estado axumita, que se desarrolla entre los siglos I y VII d.C. No está claro que en este período proto-axumita podamos hablar de una formación estatal propiamente dicha. De hecho, frente a las historias unilineales del estado, el caso del Cuerno de África mostraría, desde el inicio, una alternancia entre modelos de estatalización (como el representado por D’MT) y modelos de segmentación, como el período preaxumita. El reino de Axum supondrá un nuevo momento de estatalización.

\section{EL ESTADO HETERÁRQUICO}

El reino de Axum es mucho mejor conocido, tanto por las fuentes arqueológicas, epigráficas y numismáticas como por los textos antiguos (Phillipson 2012). Quizá por ello se ha transmitido una imagen de este que difiere poco de los estados mediterráneos y próximo-orientales en la antigüedad. Efectivamente, si nos fijamos en algunos de los rasgos más llamativos y mejor estudiados, Axum no sería 
diferente de muchos estados antiguos: tenía un rey, una clase aristocrática, una clase sacerdotal, una religión de estado, edificios públicos y de poder (palacios, templos), escritura, ciudades, un importante comercio a larga distancia que lo conectaba con el Imperio romano y la India, organizaba campañas militares más allá de sus fronteras y emitía moneda en las que aparece la efigie, el cargo y el nombre del rey. Axum participó, además, activamente en el mundo político internacional de la época (Bowersock, 2013). Estos rasgos son particularmente evidentes entre el siglo IIl y VI d.C. Pero pueden llevarnos a engaño. Una mirada más detallada a una de las ciudades axumitas puede ayudarnos a obtener una visión algo distinta .

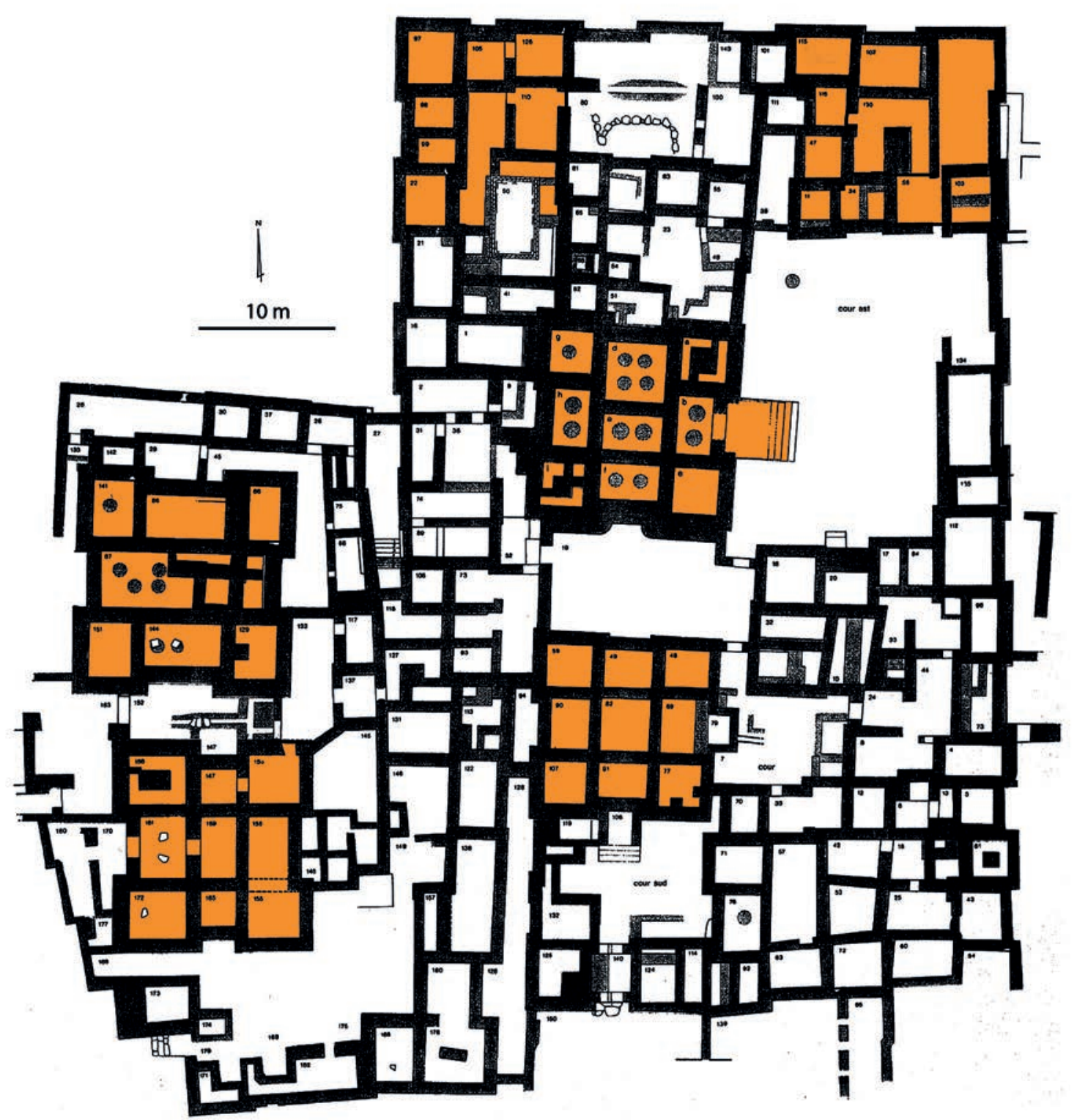

FIGURA 3. CONJUNTO DE ÉLITE EN LA CIUDAD DE MATARA CON VARIAS CASAS CON EL MÓDULO CARACTERÍSTICO (EN SOMBREADO). SE PUEDE APRECIAR LA CONTINUA AMPLIACIÓN DEL RECINTO Y DE LAS ESTRUCTURAS, SÍMBOLO DE PROSPERIDAD DE LA CASA COMO UNIDAD SOCIAL, LA CUAL DEBÍA DE ENGLOBAR LA TOTALIDAD DE LAS ESTRUCTURAS DENTRO DEL CONJUNTO. SIGLOS III-V D.C. A PARTIR DE ANFRAY (2OI2) 
La ciudad de Matara (Eritrea) fue excavada en extensión en los años 6o (Anfray 20I2). Aunque desgraciadamente las excavaciones no se llegaron a publicar en detalle, el registro material divulgado es lo suficientemente rico y elocuente para proponer algunas hipótesis. Francis Anfray sacó a la luz varios complejos, algunos de los cuales son claramente de élite y otros de las clases subalternas. Uno de los complejos pertenecía a una iglesia: el cristianismo se convirtió en la religión oficial del reino de Axum en el siglo IV. Los conjuntos de las clases populares están formados por una densa aglomeración de estructuras con múltiples habitaciones de pequeño tamaño y sin patrón aparente. El caso de los conjuntos de elite (Figura 3) es bien distinto: aquí se puede apreciar con claridad un módulo que se repite en varias ocasiones: se trata de un edificio de planta rectangular dividido en tres naves y seis habitaciones. Este módulo es el que caracteriza a los palacios, incluido el del rey de Axum en la capital, y las primeras iglesias etíopes. Que los módulos sean idénticos entre ellos y al de las edificaciones reales podría ser indicativo de un modelo sociopolítico heterárquico, en el que varios grupos poseen poder efectivo y en el que el rey es más un primus inter pares que un monarca con poder absoluto. Los símbolos materiales del poder, al fin y al cabo, suelen ser una expresión bastante clara de la naturaleza de dicho poder. El modelo del rey axumita como primus inter pares encajaría con el del «rey de reyes» de la posterior historia etíope. Por otro lado, una característica habitual en los reinos africanos, como señalé más arriba, es que los reyes o jefes estén investidos de cualidades sobrenaturales y desempeñen una función ritual importante. Que las casas de la elite y los templos axumitas compartan una misma arquitectura también es significativo a este respecto. Y la historia posterior, nuevamente, incide en esta idea, dado que existe una fuerte vinculación entre la realeza y la religión en la Etiopía medieval: no en vano, a partir de 1270 los reyes se consideran descendientes de Salomón.

Las casas de elite en Matara, cuyo núcleo central es el módulo mencionado, son más que la vivienda de una familia aristocrática. Por un lado, a su alrededor crecen estructuras adjetivas que se corresponden probablemente con almacenes, espacios agropecuarios, viviendas de dependientes y servidumbre. Por otro lado, varias estructuras de elite se sitúan en proximidad unas de otras formando conjuntos más amplios. Este modelo recuerda el de las sociedades de casa (González-Ruibal y Ruiz-Gálvez 20I6), que es esencialmente una sociedad heterárquica en la que las unidades que compiten entre sí por poder y prestigio no son familias o linajes, sino casas. Una casa puede incluir varias casas menores y la casa mayor es la real. Esto es lo que podemos estar viendo en Matara: las estructuras de módulo que se encuentran agrupadas podían formar parte de una gran casa, mientras que el palacio de Axum sería la casa grande por antonomasia: la casa del rey. Otros indicios podrían apoyar la hipótesis: por un lado, en las sociedades de casa las viviendas desempeñan un papel simbólico y material de primer orden. Ya hemos visto que esto es muy claro en el caso de Matara por la forma de organización del espacio doméstico, pero lo es también por la enorme inversión que se realiza en este. Las casas de elite desarrollan una arquitectura muy peculiar, con elementos característicos como los grandes plintos, las escaleras monumentales, los vanos enmarcados en molduras de madera o piedra y los muros de aparejo que alternan sillares en las esquinas, mampostería 
en los lienzos y vigas y que después continuarán adoptando las iglesias (Phillipson, 20I2: I2I-I25). Además, las colosales estelas funerarias de los enterramientos reales representan la fachada de una vivienda de elite típica: la metáfora de la tumba como casa es habitual en sociedades de casa. Finalmente, en la lengua amhárica, una lengua semítica hoy oficial en Etiopía, «familia» se traduce por beteseb, que es literalmente, «los que están reunidos en una casa», y el cabeza de familia es el balabet, el señor o posesor de una casa.

Matara también es expresiva de otras peculiaridades de la cultura axumita. Es distinta a las ciudades antiguas en tanto que no existe una trama urbana continua: los complejos excavados parecen más bien una especie de aldeas o barrios dentro de una constelación de núcleos habitados. El caso de Axum es similar. No existe una muralla o recinto que delimite claramente la ciudad -un rasgo que comparten muchas ciudades históricas africanas (aunque no todas como veremos). Esta fragmentación del espacio «urbano» sería un rasgo más del carácter segmentario del estado axumita. Matara sería una más entre las ciudades axumitas gobernadas por una o más casas nobles y con un elevado grado de independencia respecto al rey de reyes con sede en Axum. Otras ciudades autónomas serían Adulis, el puerto de comercio más importante de la región (Zazzaro, 20I6), y Beta Samati (Harrower et al, 2019). No solo el interior del reino era sociopolíticamente heterogéneo, las fronteras del reino axumita también siguieron siendo porosas y difusas, si bien Axum se involucra más en sus fronteras, por lo que podemos colegir por los testimonios epigráficos: organiza razias hacia las tierras bajas de Sudán, captura esclavos, reasienta pueblos enteros y llega hasta Meroe (Pankhurst, 1977).

\section{COLAPSO}

En la historia de Etiopía se aprecia continuamente una tensión entre fuerzas centrífugas y centrípetas. En los momentos donde predominan las fuerzas centrípetas asistimos a momentos de consolidación y expansión del estado. El caso del reino de Axum es un ejemplo de ello. Las fuerzas centrífugas, sin embargo, se impusieron a partir del siglo VIl. Lo hicieron por una combinación de factores, como el declive del comercio a larga distancia por el Mar Rojo, la peste de Justiniano, la expansión del Islam y probablemente una sobreexplotación de los suelos agrícolas derivada del crecimiento demográfico (Butzer, I98I). En los momentos de debilitamiento estatal surgen contrapoderes y con frecuencia el eje del poder se desplaza hacia los márgenes, que ganan mayor autonomía: este proceso comienza ya a fines de época axumita, como lo demuestran recientes excavaciones en el sitio de Mifsas Bahri (Gaudiello y Yule 20I7), un complejo situado a Ioo $\mathrm{km}$ al sur del siguiente núcleo axumita conocido y que se data entre el 500 y 700 d.C. Pero el centro de gravedad hacia el final de época axumita se desplaza, sobre todo, hacia el este, que es donde se documentan los principales monasterios de fines del I milenio d.C. (Phillipson, 20I2: 2I2-223).

Tras la desaparición de Axum que es completa en el siglo X, el panorama político se fragmenta y el núcleo del poder se mueve hacia al sur, hacia el altiplano central etíope, un territorio ocupado por comunidades paganas hablantes de lenguas cuchíticas 
(frente a las cristianas y semíticas de Axum). Es muy poco lo que sabemos del período comprendido entre 800 y 1270 d.C. en el norte del altiplano, del que apenas contamos con fuentes escritas y sobre el que no se han llevado a cabo investigaciones arqueológicas. En el este y sudeste del altiplano, en cambio se ha documentado el surgimiento de nuevos grupos culturales en este mismo período (Fauvelle 2020).

Entre ellas se encuentra la Cultura de Shay (Fauvelle y Poissonier 2016), caracterizada por enterramientos colectivos en los que se depositan restos humanos desarticulados con ajuares compuestos por cerámicas muy características (botellas y cuencos discoides), cuentas de pasta vítrea procedentes del comercio índico y algunas armas. Aunque los rituales funerarios son paganos (las tumbas se reabrían y recibían más enterramientos, como en el megalitismo europeo), en algunas cerámicas han aparecido cruces, lo que indica que los miembros de esta cultura conocían el cristianismo y posiblemente estaban adoptando elementos de este. La Cultura de Shay en su etapa final se encuentra en una posición fronteriza entre el reino cristiano de Etiopía al oeste y los reinos musulmanes al este. Pero en un principio es posible que fuera la cultura dominante en buena parte del altiplano, dado que se han encontrado restos arqueológicos de este tipo hasta el Lago Tana, en el centro mismo de la meseta. Pese a que han aparecido elementos de importación, lo cierto es que el tipo de enterramientos indica más bien una sociedad de tipo segmentario, no centralizada y escasamente jerarquizada.

Más al este, en las montañas Chercher, se ha documentado otra tradición pagana con enterramientos colectivos en túmulos que arranca de la época en que se hunde el reino de Axum, hacia el siglo VIII d.C. (Joussaume 20I7). Al contrario que en la Cultura de Shay, en este caso sí se conocen asentamientos: se trata de recintos amurallados con aparejo ciclópeo que posiblemente se utilizaron solo como refugio en momentos de conflicto. En esta misma región se desarrollaron, a partir del siglo XIl y bajo influencia islámica, ciudades propiamente dichas (Joussaume y Joussaume I974). No está claro que en momento preislámicos y fuera de épocas de peligro las gentes de Chercher llegasen a establecerse en asentamientos permanentes.

El colapso y la fragmentación de Axum no significa que desapareciera la tradición estatal del todo. En el caso de Etiopía, la tradición se mantiene, en buena medida, gracias a la religión. El peculiar cristianismo etíope actúa como repositorio cultural e institucional de primer orden. La crisis del siglo VII supone la desaparición de varios símbolos clave del estado: los palacios, la escritura monumental, la moneda. Pero la Iglesia mantiene tres pilares fundamentales en la identidad estatal: la religión, la escritura y la memoria de la monarquía y lo hace sobre todo en monasterios localizados en lugares remotos de la periferia de Axum.

\section{EL ESTADO HETERÓCLITO}

A partir de mediados del siglo XIII, regresa la tradición cristiana estatal, ahora mezclada con las tradiciones paganas y cuchíticas del altiplano. El estado tendrá su núcleo en lo que había sido la periferia de Axum, en el altiplano central etíope, con Lalibela como su núcleo simbólico. En estos momentos se crea una tradición 
cultural bien definida que llega, en muchos sentidos, hasta hoy. También desde un punto de vista material: la arquitectura, la cerámica, el adorno corporal o el vestido no sufren grandes transformaciones entre el siglo XIII al XXI. El caso de la cerámica es particularmente interesante: la escasa variación hace difícil diferenciar un sitio del siglo XIV de uno del XIX, por ejemplo. Esta identidad cultural homogénea no va de la mano de formas de dominación igualmente homogéneas: es por ello que el reino cristiano del altiplano desde el siglo XIII hasta los intentos de modernización que comienzan a mediados del siglo XIX se puede definir como un estado heteróclito: un estado irregular y heterogéneo, sin bases permanentes, que no ejerce un control férreo sobre el territorio, que convive con bolsas de otredad en su interior y donde el rey tiene que competir, como primus inter pares, con otros reyes. Estos rasgos son característicos de las formaciones estatales en el Cuerno de África a lo largo de tres milenios (también en la actualidad), pero es probablemente en el segundo milenio (el período a veces denominado feudal o medieval), donde resultan más obvios.

Así pues, la recuperación del estado cristiano no significa que vuelvan todos los elementos que lo caracterizaron en época axumita y que se suelen identificar con una mayor centralización y un carácter típicamente estatal. De hecho, la mayor parte no lo hacen: ni las acuñaciones, ni las ciudades, ni las inscripciones monumentales, ni el concepto de capital permanente del estado. La capital, por ejemplo, será itinerante hasta I886, cuando se funda Addis Abeba, excepto por un breve período entre inicios del siglo XVIl y fines del XVIII en el cual la ciudad de Gondar se convierte en el centro político. La capital está allí donde reside el rey, en su campamento (gebi) en el cual no hay estructuras de piedra, sino chozas y tiendas.

Otro aspecto que diferencia el nuevo reino del antiguo es su falta de implicación en el comercio a larga distancia. En las excavaciones llevadas a cabo en sitios comprendidos entre el siglo XIIl y el XIX no ha aparecido prácticamente ningún elemento de importancia (González-Ruibal 2020). Esto contrasta vivamente con los reinos islámicos del Cuerno de África en esas mismas fechas (Fauvelle-Aymar y Hirsch 20II; González-Ruibal 2020). Da la sensación de que la sociedad que emerge en el siglo XIII al mismo tiempo que desarrolla una fuerte personalidad cultural, se vuelve muy refractaria a las influencias exteriores. En parte, el carácter refractario es lo que le permite mantener esa misma personalidad a lo largo de los siglos y en un entorno cada vez más extraño y hostil. Conviene recordar que para el siglo XV el reino de Etiopía era ya el único estado cristiano que sobrevivía en África. La religión cristiana y la Iglesia, que habían servido para mantener la memoria y la cultura estatal durante la época oscura de los siglos VIII al XIII, se convierten a partir de I270, fecha oficial de la restauración de la dinastía salomónica, aún más en elementos definitorios en la identidad y el estado etíopes (Tadesse Tamrat, 1972). La cultura material desempeña un papel importante en este proceso: desde las iglesias y monasterios que definen de forma decisiva el paisaje cultural, empezando por el fastuoso conjunto de templos excavados en la roca de Lalibela (Derat et al., 202I), hasta las cruces que tatúan o cubren el cuerpo de los etíopes (Figura 4).

La lglesia desempeña otro papel clave en el nuevo estado. Porque el reino cristiano se extiende mucho más allá de los límites tradicionales, tanto por el oeste como por el sur. Entra de lleno en territorios que habían tenido contacto muy limitado con 
el norte cristiano y estatal y mantenían su independencia. En algunos casos, habían sido espacios de depredación desde hacía siglos (Pankhurst, I977): en las tierras bajas del oeste, por ejemplo, en la actual zona fronteriza con Sudán, acudían los nobles a cazar, cobrar tributo y capturar esclavos. A partir del siglo XIII en algunas zonas periféricas se comienza a establecer un control efectivo del territorio y los monasterios sirven precisamente para consolidar la presencia del poder real (Derat, 2003). Los centros monásticos son la avanzadilla del estado, construyen estado y reproducen el paisaje cultural en las periferias.

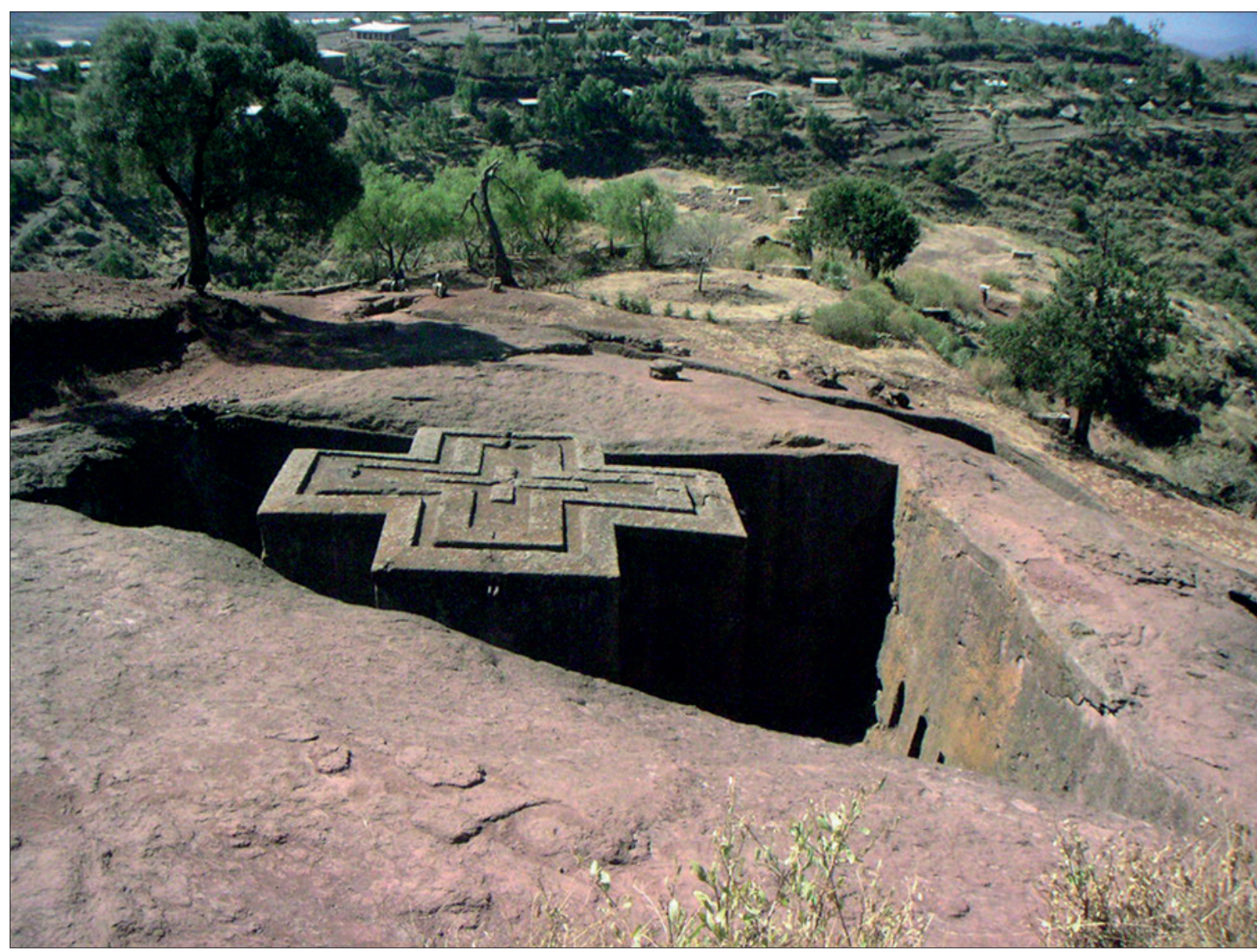

FIGURA 4. IGLESIA DE SAN JORGE EXCAVADA EN LA ROCA EN LALIBELA (HACIA EL SIGLO XIII), PARTE DE UN CONJUNTO ARQUITECTÓNICO QUE ACTÚO COMO NÚCLEO DEL PODER REAL Y RELIGIOSO DE LA ETIOPÍA CRISTIANA. Foto del autor

La expansión del reino etíope dejó multitud de bolsas de población no asimilada por lo general hablantes de lenguas agäw (cuchíticas): en el altiplano septentrional tenemos a los K’ämant', cuya religión es una mezcla de elementos paganos y judíos, los Beta Israel (judíos), los K'unfäl y los Wäyto (ambos paganos hasta hace poco, los segundo islamizados) (Gamst I969; Quirin I998; Desalegn Amsalu 2016). Además de ser cultural, lingüística y religiosamente distintos a los grupos dominantes, también son distintos -o más bien complementarios- desde un punto de vista económico. Así, los Beta Israel realizan trabajos de curtido y alfarería que son despreciados por la sociedad amhara dominante, los Wäyto se especializan en la caza y la pesca y la 
realización de artesanías con papiro, y los K'ünfäl proporcionan miel y productos del bosque a los habitantes del altiplano. Que estos grupos hayan sobrevivido hasta la actualidad tiene que ver con la lógica del estado tradicional etíope, que nunca trató de homogeneizar el espacio sobre el que proclamaba su soberanía. De la misma manera, aunque reivindicaba un amplio territorio en su periferia oriental, hacia Sudán, jamás trató de conquistarlo en la práctica. La noción de dominio territorial efectiva es ajena a la racionalidad política etíope hasta finales del siglo XIX. La soberanía se ejerce mediante el cobro de tributo o las expediciones militares cada cierto tiempo. Así, en las investigaciones de la periferia occidental de Etiopía apenas documentamos objetos que procedan del comercio con el estado del altiplano, pero sí hemos descubierto poblados arrasados por razias (provenientes de Sudán o de Etiopía, resulta difícil saber) que es la forma más habitual de mostrar el poder del estado sobre los espacios de frontera (González-Ruibal y Falquina, 20I7; González Ruibal, 202I).

\section{SULTANATOS Y NÓMADAS}

Al mismo tiempo que revive el estado cristiano, se desarrollan en el este del Cuerno otros estados de naturaleza muy distinta (Figura 5): los sultanatos islámicos (Fauvelle-Aymar y Hirsch, 20II; Chekroun y Hirsch, 2020). La presencia islámica se deja notar desde el siglo VII en las islas Dahlak en la costa eritrea y posteriormente en la zona oriental de Eritrea y Tigray. Posteriormente, hacia el siglo X, se funda en el este del altiplano, en la región de Shäwa, el primero de los estados islámicos. Le seguirán el sultanato de Ifat en I286 y el de Adal en I4I5, que pervive hasta fines del siglo XVl y que se extienden entre el este de Etiopía, Somalilandia, Puntlandia (Somalia) y Yibuti. Estas formaciones políticas son, en muchos sentidos, el reverso del reino de Etiopía: frente al mundo cristiano, rural y aislado tenemos el mundo islámico, urbano y conectado con las grandes redes de comercio del Océano Índico. Frente al carácter profundamente local de Etiopía, el cosmopolitismo de los estados musulmanes (Insoll et al., 202I).

Las investigaciones llevadas a cabo en Somalilandia y Etiopía muestran la proliferación de asentamientos estables con arquitectura en piedra a principios del Il milenio (Curle, I937; Hirsch y Fauvelle-Aymar, 2004; Insoll et al., 202I). Aunque se suele hablar de ciudades, lo cierto es que existe una amplia tipología de asentamientos estables: desde diminutas aldeas o caseríos a ciudades propiamente dichas, con más de ro hectáreas y edificios públicos (mezquitas). Al igual que sucedía en Etiopía, la creación de estas formaciones políticas no significa la aparición de espacios estatales homogéneos. En realidad se trata de territorios mosaico, fragmentados, heterogéneos y en los que existen diversas culturas, formas de vida y organización social. En el caso de los estados islámicos, lo que perviven son sociedades nómadas, cuyo origen se puede rastrear hasta el III milenio a.C. y que continúan en la actualidad. Se podría hablar, hasta cierto punto, de una sociedad dual, cada una con sus normas, su cultura material y su forma de construir y experimentar el paisaje. En el caso de los nómadas, siguen desplazándose por rutas 
que se habían establecido siglos o milenios antes y su paisaje se basa en los túmulos funerarios de piedra y los espacios de agregación (en los cuales aparecen, a partir de los siglos XII o XIII, las mezquitas), frente a los paisajes cultivados y las ciudades que representan el núcleo del estado. Estos dos paisajes conviven, a veces en conflicto, a lo largo de los siglos. En ocasiones lo hacen por separado, en ocasiones confluyen: las rutas nómadas, por ejemplo, las siguen también las caravanas de mercaderes que llevan esclavos y marfil desde el sur de Etiopía a la costa y perfumes, vasijas, telas y cuentas de vidrio de la costa a las ciudades del interior.

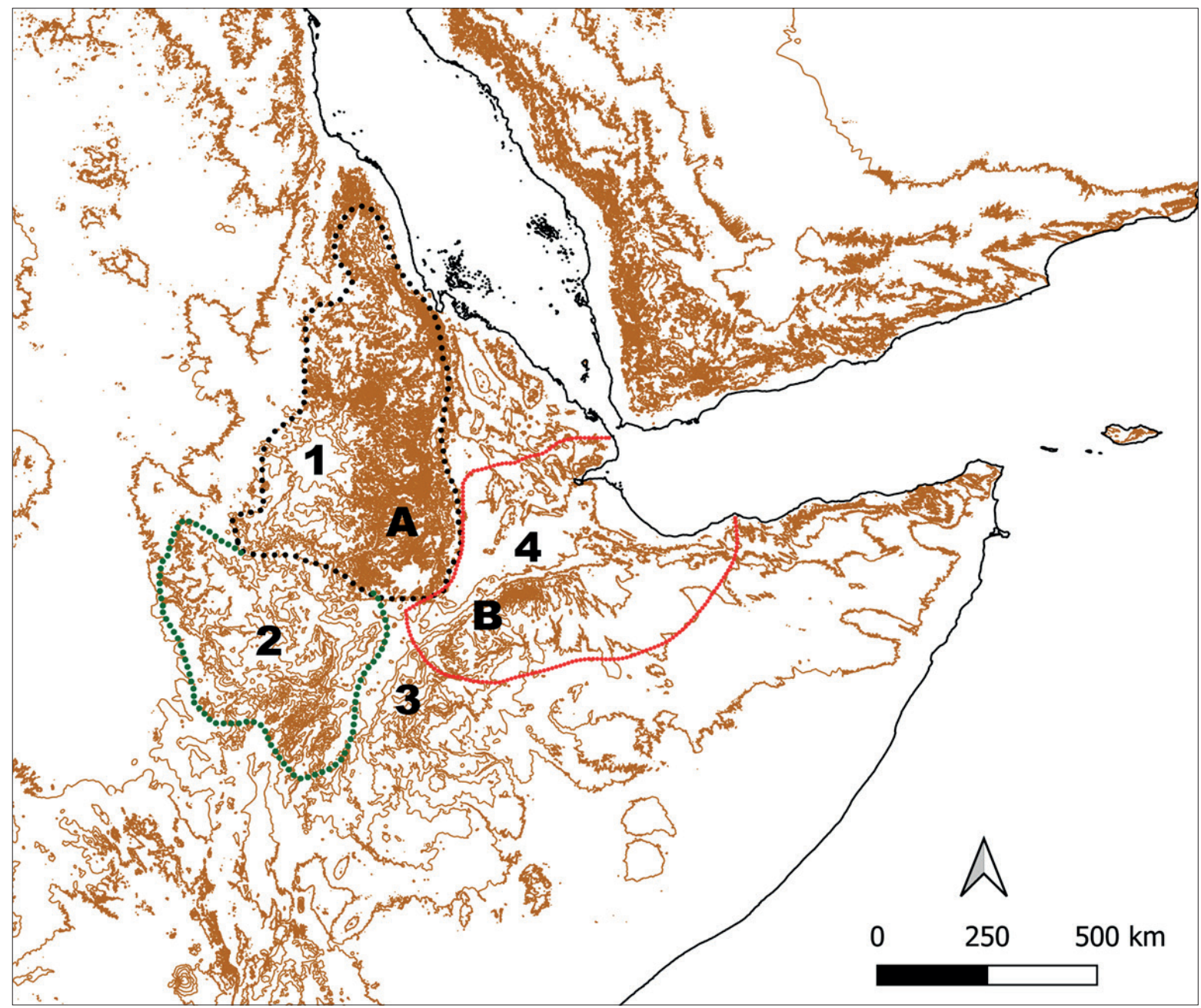

FIGURA 5. ORGANIZACIONES SOCIOPOLÍTICAS JERARQUIZADAS EN EL CUERNO DE ÁFRICA HACIA $1200-1550$. 1. REINO CRISTIANO DE ETIOPÍA; 2. REINOS OMÓTICOS; 3. JEFATURAS CUCHÍTICAS (TIYA); 4. SULTANATOS ISLÁMICOS. A. CULTURA DE SHAY (CA. 900-1300); B. CULTURA DE CHERCHER (CA. 800-1200). Mapa del autor

Además de las rutas, hay otros dos espacios comunes para nómadas y sedentarios: los santuarios y las ferias (González Ruibal y Torres 2018). Los santuarios suelen situarse en encrucijadas naturales y crecen a partir de un núcleo preislámico, en ocasiones muy antiguo. Ese núcleo puede estar representado por un gran túmulo donde se considera que está enterrado el ancestro de un clan o un hombre santo 
(Mire 2015). A su alrededor crecen las tumbas, cuya tipología va cambiando con el tiempo, y también los espacios de oración, meditación y retiro propios de la rama sufí del Islam. Por lo que se refiere a las ferias o espacios de comercio abiertos, estos existían ya en el siglo I a.C., si no antes. Están recogidos en el Periplo del Mar Eritreo, de mediados del siglo I d.C. (Casson 2012), que menciona los lugares de comercio de Avalites, Malao, Mundu, Mosyllon, Aromaton Emporion y Opone, entre el Golfo de Tadjura en Yibuti y el Cabo Guardafui en Somalia. Tras un período oscuro comprendido entre los siglos VIl y XII, las ferias vuelven a resurgir con fuerza en el siglo XII, esta vez en el marco del comercio islámico a larga distancia. En estos espacios de intercambio aparecen materiales de las más variadas procedencias: Egipto, Irán, India, China, el sudeste asiático (Figura 6).

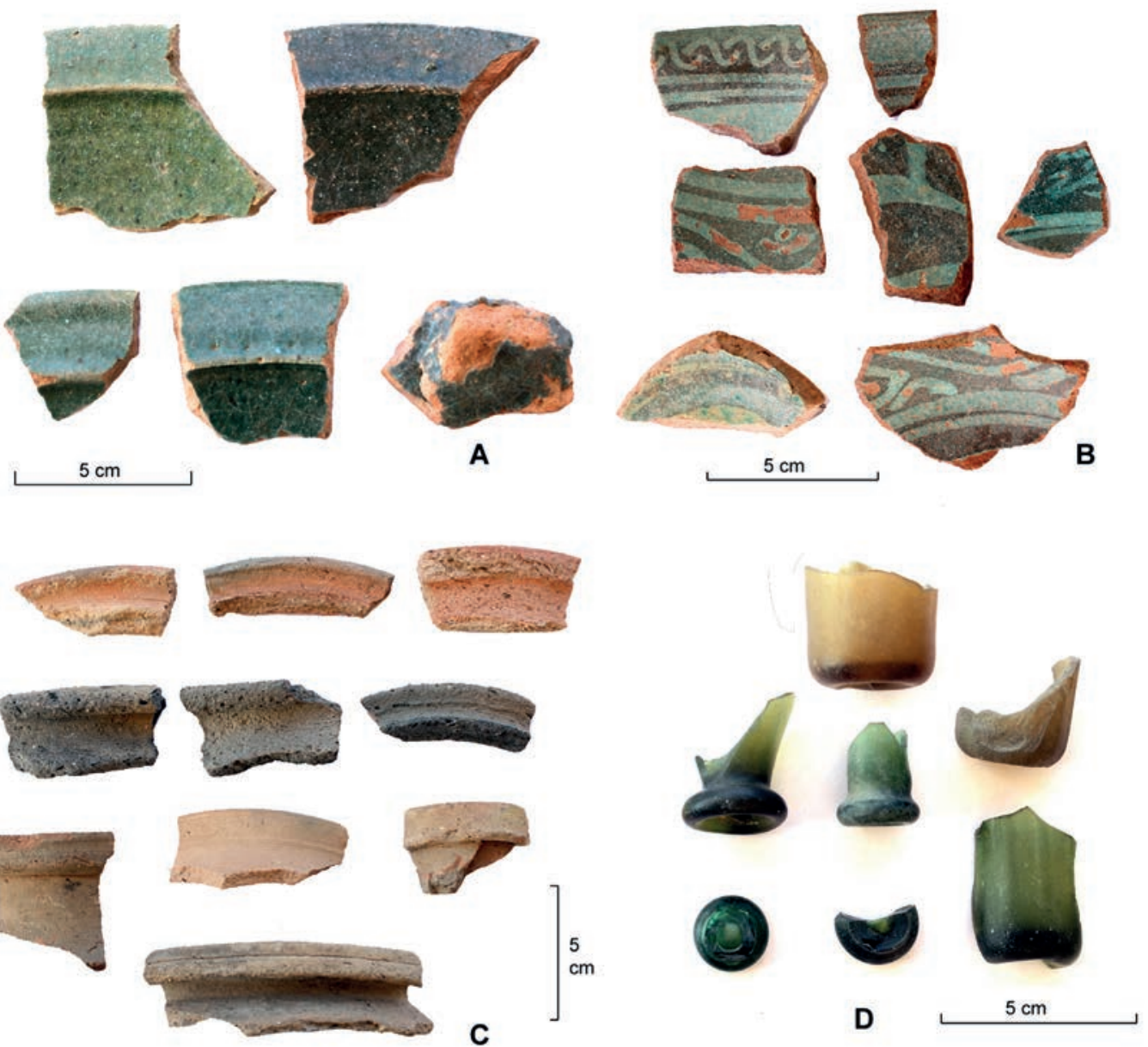

FIGURA 6. MATERIALES DE IMPORTACIÓN EN LA FERIA DE SIYARA: A. CERÁMICA VIDRIADA DE IRÁN (S. XV-XVI); B. CERÁMICA VIDRIADA DE YEMEN (S. XV-XVI); C. CERÁMICA DE COCINA DE LA INDIA (S. XI-XIV); D. RESTOS DE PERFUMARIOS Y UNGÜENTARIOS DE EGIPTO Y OTRAS PROCEDENCIAS (S. XI-XVI). Lámina del autor

Sin embargo, al contrario de lo que sucede en la costa entre Egipto y Yibuti y posteriormente en las costas de Asia, los mercados del litoral somalí no se convierten en ciudades salvo en contadas y tardías ocasiones (Zeila en el siglo IX o X, Berbera en el siglo XV). De hecho, probablemente nunca llegan a ser puntos de fijos de 
comercio: son los nómadas quienes deciden dónde y cuándo se comercia, según su movilidad estacional y según sus alianzas, conflictos e intereses económicos y políticos: de ahí que haya más yacimientos que puntos mencionados en el Periplo.

Este paisaje comercial flexible y cambiante, al albur de los pastores, perdura hasta inicios del siglo XX, de hecho: pese a que los británicos privilegian tres puertos de comercio (Zeila, Bulhar y Berbera), siguen existiendo multitud de puertos menores, fondeaderos naturales, que canalizan parte del intercambio (Karin, Maydh, Ceelayo, Bender Qassim, Qandala...) (Pankhurst 1966). Como en la Edad Media, la racionalidad del estado y la racionalidad de los nómadas se ven obligadas a convivir. Para los pastores, el paisaje flexible, los espacios de intercambio abiertos, las rutas cambiantes son garantía de independencia y una forma de resistencia al control de los estados -sea el sultanato de Adal o el estado colonial del siglo XX.

El sultanato de Adal entra en decadencia a mediados del siglo XVI por una combinación de factores (Abir, 2013[1980]): por un lado, la yihad con Etiopía, que supone un desgaste enorme para el sultanato y que abre la puerta a migraciones de pastores desde el sur (Oromo). La propia Etiopía sufre un declive importante a raíz del mismo conflicto y pierde a manos de los Oromo una buena parte del territorio que había adquirido en el sur durante la expansión del siglo precedente. Por otro lado, desde inicios del XVI, los portugueses irrumpen en el Mar Rojo y el comercio a larga distancia, que había sido tan importante para Adal, entra en crisis. Así como otras regiones afectadas por la expansión portuguesa logran recuperarse durante la segunda mitad del XVI, el sultanato de Adal no llega a hacerlo: el comercio se desplaza al sur de Arabia y el colapso de las ciudades islámicas hace que se pierda un mercado de primer orden para el comercio internacional. Al mismo tiempo, los otomanos llegan también al Mar Rojo y entran en conflicto con los portugueses. Durante esta época entramos en un período del que sabemos muy poco arqueológica e históricamente. En el sur de Somalia, el colapso tarda un poco más en llegar que en el Golfo de Adén, pero para el siglo XVII, Mogadiscio, que había sido una de las ciudades más importantes de la costa swahili del este de África (Chittick, I982), había quedado reducida a su mínima expresión.

Las ciudades desaparecieron tan rápidamente como habían aparecido, lo cual pone de manifiesto la flexibilidad del modelo social de los territorios somalíes. Estamos hablando de sociedades de pastores que pueden revertir muy rápidamente a un estilo de vida nómada, porque son capaces de convertir la riqueza acumulada en animales y porque nunca perdieron la conexión con el mundo pastoril. Por otro lado, las familias más urbanas y orientadas al comercio son suficientemente cosmopolitas para poder buscar refugio y fortuna en comunidades de la diáspora comercial fuera del Cuerno de África. Así pues, en la larga historia de Somalilandia, los asentamientos estables aparecen como una breve anomalía: un período de apenas 400 años de sedentarismo parcial en una larguísima historia de movilidad. Es probable que el modo de vida pastoril hubiera sido el dominante más allá de fines del siglo XIX sino fuera por la intervención colonial en el último cuarto del siglo XIX, que volvió a situar el paisaje urbano junto al nómada. 


\section{EL ESTADO AMURALLADO}

Decía más arriba que a partir del siglo XIV el estado etíope renacido se expande hacia el sur. Esta expansión le llevará a entrar en colisión con otras formaciones sociales jerarquizadas: los estados omóticos y cuchíticos (por las familias lingüísticas que se hablan en sus territorios) que se sitúan en la cuenca del río Omo y los lagos del Rift respectivamente. Estas formaciones políticas parecen desarrollarse a partir del siglo XIII, una fecha que sugieren las tradiciones orales y que confirma la arqueología (Arthur et al. 2020). En estos momentos comienzan a emerger también reinos más al sur, en Uganda. Es evidente que hay factores endógenos que explican estos desarrollos: el sur de Etiopía es una zona muy fértil y en la que se cultiva una planta, el ensete (Ensete ventricosum), que por su gran productividad, es capaz de sostener altas densidades de población. Todo indica que desde inicios del Il milenio, sino antes, se produce un gran crecimiento demográfico en el sur de Etiopía, de la mano de una intensificación agrícola. Esta intensificación supone una fuerte transformación del paisaje mediante aterrazamientos y fosos (Figura 7): una forma de construir el espacio agrario que llega hasta la actualidad (Watson, 2009). Sobre este trasfondo inciden elementos llegados del norte. Las influencias septentrionales son sin duda anteriores a la expansión del reino cristiano; hay que tener en cuenta que previamente a esta, los reinos omóticos llegaban hasta el valle del Nilo Azul y estos eran, por tanto, vecinos del Reino de Etiopía. Es más, tenemos que considerar que las influencias eran bidireccionales: en la realeza etíope hay elementos muy semejantes a los del sur y pueden tener que ver con un trasfondo cultural compartido y que incluye elementos como la importancia de los símbolos y los materiales que los encarnan, los mitos de origen o la importancia del linaje (Haberland I965).

Una forma en que elementos del norte llegaron al sur fue a través de migraciones de miembros de la sociedad dominante etíope que se desplazaron al sur, entroncaron con las elites omóticas y cuchíticas y crearon nuevas dinastías mestizas. De esta llegada de gente del norte tenemos testimonio en las historias orales que se han documentado, en las que se habla de la llegada de extranjeros blancos. En ocasiones el nombre del primer rey hace referencia a ese origen extranjero: por ejemplo, Nech' Taro («Rey Blanco»). Los antropólogos coloniales interpretaron esto como la llegada de portugueses, (Grottanelli, I940) que habrían fundado los reinos del sur, pero, por un lado, todo indica que los «reyes blancos» son muy anteriores a la llegada de los portugueses, por otro, la gente del norte de Etiopía es de piel más clara que los del sur y rasgos caucasoides, con lo que habrían sido percibidos como racialmente distintos (como, de hecho, sucede en la actualidad). Finalmente, cabría esperar que la llegada de los portugueses hubiese dejado una huella más fuerte en mitos o costumbres, pero no hay evidencia alguna de ella.

De lo que se trata, más bien, es de un ejemplo característico de «sociedad de frontera», tal como la describe Igor Kopytoff (I987): este tipo de sociedades surgen por el desplazamiento de uno o más miembros de una determinada formación política hacia la periferia del territorio, donde fundan una nueva entidad política tras entroncar con familias locales. Esta nueva entidad mantiene lazos simbólicos con la formación original, que se van debilitando a lo largo del tiempo. Los jefes 
extranjeros basan parte de su poder en la mística del forastero y en los saberes rituales y símbolos que traen consigo.

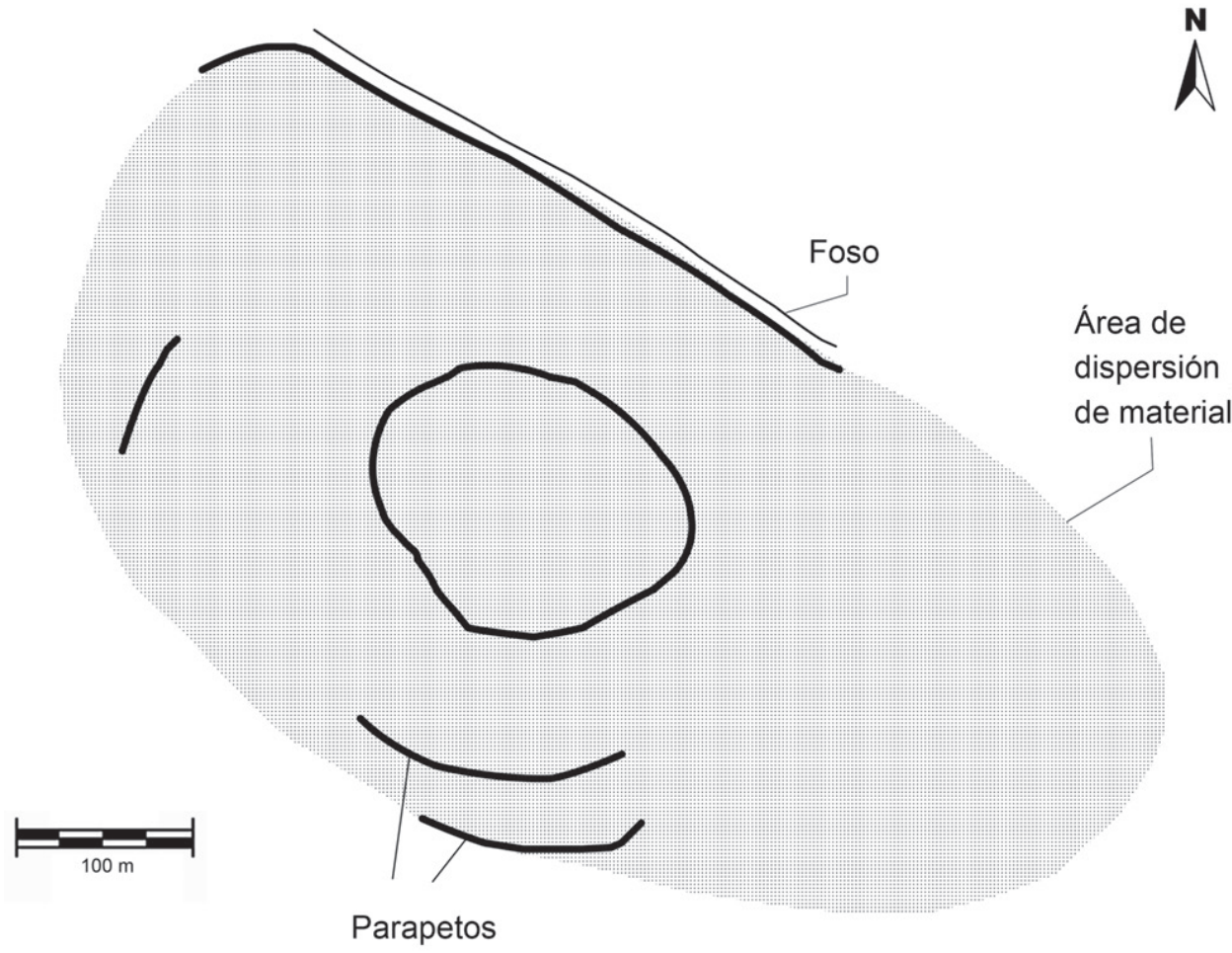

FIGURA 7.ASENTAMIENTO FORTIFICADO DE GARA GUTE, EN EL REINO DE ANFILLO (SIGLOS XVII-XVIII). Plano del autor

Uno de los aspectos definitorios de los estados omóticos del sur de Etiopía es la preocupación con los límites. Así como el Reino de Etiopía poseía unas fronteras difusas que sus monarcas no se preocupaban en marcar, en el caso de los reinos omóticos sucede todo lo contrario. Existe, en toco caso, una obsesión con las fronteras. En algunos casos, como en Dawro o Anfillo, todo el reino se rodea de fosos o murallas. Las de Dawro se extienden a lo largo de i8o kilómetros (Hailu Zeleke, 2007). Los propios poblados están también rodeados de fosos y parapetos. A su vez, esta obsesión se refleja en el propio cuerpo del soberano, que no puede ser visto ni tocado y que se rodea de toda una serie de prohibiciones rituales, dentro de una concepción divina de la monarquía (Donham, I980). En esto, muestra similitudes importantes con otros reinos africanos.

A partir del siglo XVI, con las invasiones oromo (Mohammed Hassen, I990), la protección adquirió una dimensión cada vez más práctica y, de hecho, las enrevesadas fortificaciones sirvieron en algunos casos para frustrar los intentos de conquista por parte de los pastores. No obstante, la mayor parte de los reinos quedaron deshechos y ocupados por los recién llegados, que en buena medida absorbieron las tradiciones de los conquistados. Esta desbandada dio lugar a su vez a procesos muy interesantes de creación de nuevas sociedades de frontera: en algunos casos, las elites y sus dependientes huyeron ante el avance oromo y fundaron estados en las periferias, 
creando relaciones vasalláticas con las comunidades indígenas de las tierras que ocuparon (Grottanelli I940).

Un excelente ejemplo de ello es el Reino de Anfillo, establecido hacia I6oo en el límite más oriental del altiplano meridional, frente a Sudán del Sur (González-Ruibal, 20I4: 250-255). Las elites omóticas que huyeron a Anfillo, los busase, sometieron a los grupos locales, hablantes de lenguas koman (un grupo de la familia nilo-sahariana) y que se dedicaban a la agricultura de roza, la caza, la pesca y la recolección. Estos grupos quedaron convertidos en una clase subalterna: los mao. Perdieron su lengua y la mayor parte de sus costumbres y adoptaron las de sus señores. Este proceso se había producido ya en otras ocasiones y clases subalternas similares, conocidas como manjo o mawo (Getachew Robo Gebremariam, 202I), existen en otros reinos omóticos y llegan hasta la actualidad: hoy en día forman comunidades marginadas que desarrollan actividades percibidas como de bajo estatus, contaminantes o desagradables (curtido, alfarería, circuncisión, entierros). De hecho, lo que se observa en el sur es algo muy parecido a lo que describimos en el norte: la expansión de un grupo dominante da lugar a la creación de comunidades subalternas especializadas. La diferencia es que en el caso del Reino de Etiopía ocupan sus propios territorios y mantienen un cierto grado de autonomía, mientras que en el sur suelen quedar incorporadas dentro del grupo dominante y simplemente viven en aldeas o barrios separados. Digo normalmente porque también existen comunidades subalternas autónomas en relación a los reinos omóticos: es el caso de los grupos conocidos como «mao del norte» (González-Ruibal, 20I4). En este caso, las relaciones con la sociedad dominante y su plasmación espacial son más semejantes a las de los grupos subalternos del Reino de Etiopía: se trata de comunidades que viven en una relación de simbiosis con los grupos dominantes (omóticos inicialmente, actualmente oromo), en un territorio adyacente, sin haber sido completamente integrados en la sociedad mayoritaria - un proceso que está culminando solo en la actualidad.

Al este de los reinos omóticos se desarrollaron sociedades jerarquizadas de lengua cuchítica, en la zona de los lagos del Rift. Es interesante la distinta inversión material de unos y otros: mientras entre los omóticos se observa una gran monumentalización del espacio habitado, en el caso de los cuchíticos es, al contrario, el espacio funerario en el que se realizan los mayores esfuerzos. El elemento material característico es la estela (Joussaume, I996; Joussaume et al., 2010): se han registrados campos de estelas, a veces con cientos de ellas, que se corresponden con tumbas. Las estelas tienen grabados motivos geométricos que recuerdan a las escarificaciones corporales y armas (Figura 8): las más llamativas son espadas, que sin duda proceden de los reinos del norte, bien la Etiopía cristiana o los sultanatos del este. En el interior de las tumbas se han documentado algunos elementos de importación, como pulseras y cuentas de cornalina y pasta vítrea. Es poco lo que sabemos de esta sociedad, pero tanto la distribución diferencial de importaciones como la diversidad de estelas -algunas más y mejor decoradas que otras y más monumentales- indican diferencias de estatus. La cronología absoluta de estos yacimientos comprende el siglo XI al XIV y coincide con un momento álgido de expansión de las formaciones estatales en el Cuerno de África, como estamos viendo. 


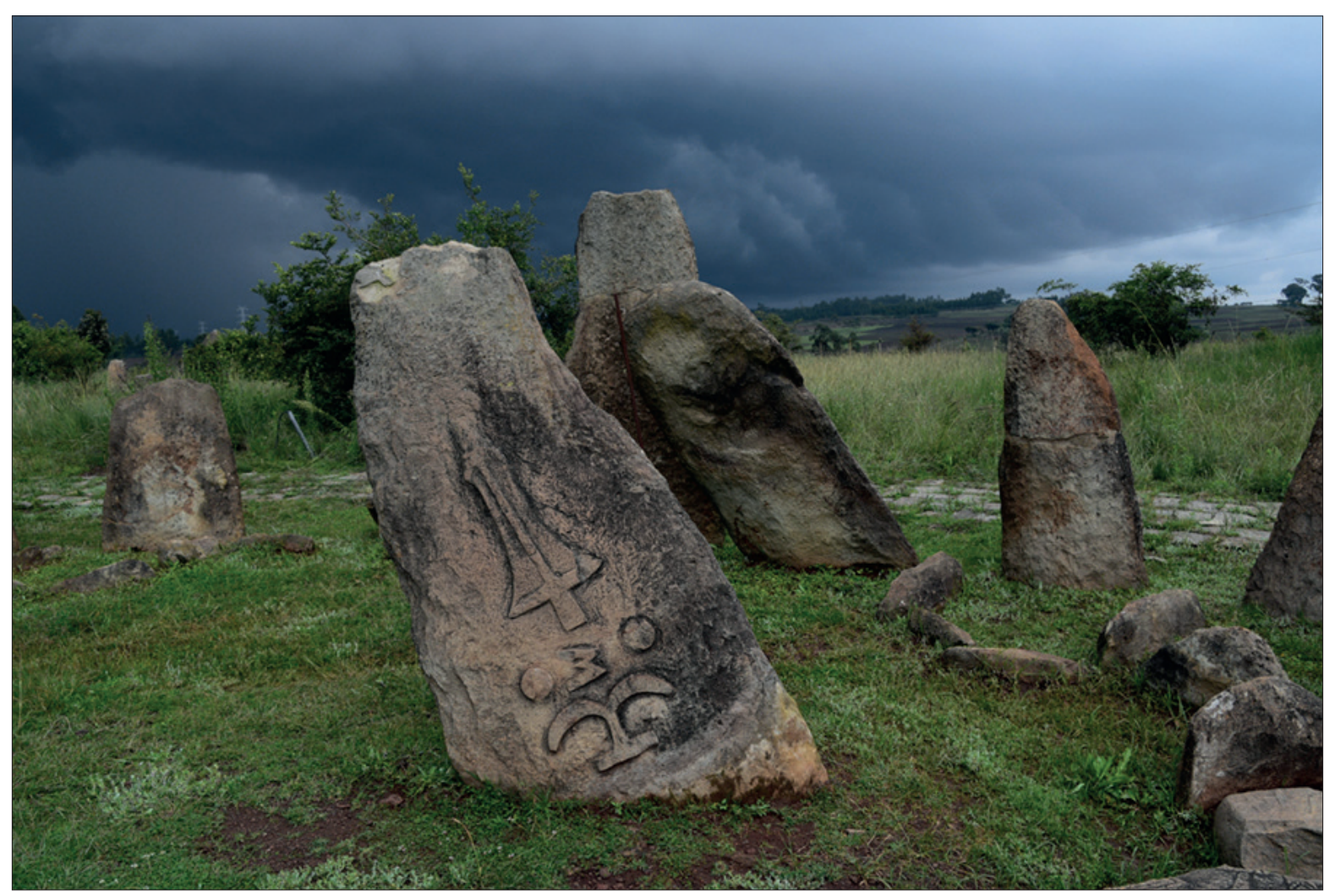

FIgURA 8. CAMPO DE ESTELAS DE TIYA (HACIA EL SIgLO XIII). Richard Mortel, Wikimedia Commons

\section{ESTADOS DE FRONTERA}

El último tipo de formación estatal a la que me referiré es el que se desarrolla a lo largo de la frontera etíope-sudanesa. El territorio del actual Sudán cuenta con una trayectoria estatal aun más antigua que Etiopía: se puede retrotraer a inicios del Il milenio a.C. en la localidad de Kerma, la primera sociedad fuertemente jerarquizada y con elementos característicos del estado. Los centros estatales se fueron desplazando hacia el sur: Meroe está aguas arriba del Nilo, Soba, la capital del principal reino cristiano de Sudán Alodia, se sitúa cerca del actual Jartum y Sennar, la sede del Sultanato Funj, se ubica aguas arriba del Nilo Azul. La migración de individuos y colectivos procedentes de Sudán hacia el piedemonte etíope desde inicios del 11 milenio d.C. dio lugar a formaciones sociales peculiares, algunas de carácter estatal o proto-estatal y otras de tipo segmentario (Spaulding I974). El proceso de estatalización es tardío y no llegó a completarse porque fue interrumpido por la expansión del moderno estado etíope a fines del siglo XIX, lo que supone la ocupación efectiva de su periferia hacia I9oo. Existen cuatro sociedades de frontera que emergen entre el siglo XVII y XIX: los Tekruri, los Ganjar, los Hamaj y los Berta. En el primer caso se trata de peregrinos del oeste de África que iban camino de la Meca y se acabaron estableciendo en distintos puntos de la frontera, los principales son Metema y Nuqara (Robison, I926; Garretson 
I982), en el noroeste de Etiopía. Los Tekruri llegaron a formar en el siglo XVIII dos micro-estados fronterizos con sus propios jeques, aunque en relación vasallática con los estados vecinos. El descubrimiento de un asentamiento vinculado a este grupo, que realizamos en 2015 en la localidad de Lay Gubay (Metema), sacó a la luz un interesante repertorio material en el que se mezclan elementos sudaneses y etíopes: una perfecta metáfora del carácter fronterizo de esta comunidad y su vocación comercial.

De los Ganjar se sabe muy poco. Los menciona el viajero escocés James Scott a finales del siglo XVIIl, quien recoge una historia sobre su origen: aparentemente, eran esclavos que habrían migrado desde el oeste hacia Etiopía huyendo de sus amos en el Sultanato de Funj en Sudán. Se asentaron al sur de la zona Tekruri, entre los ríos Rahad y Dinder. En esta zona sabemos que había había hacia I9oo comunidades de Kunjara, un grupo procedente de Darfur (es decir, también del oeste). Es posible que Ganjar y Kunjara sean lo mismo. En este caso, nada parece indicar que hubieran formado una sociedad de tipo jerarquizado.

Los Hamaj y los Bertha migraron del este de Sudán hacia Etiopía hacia I685 (Triulzi, 198I), para escapar de la expansión del Sultanato Funj. Los Hamaj se asentaron entre el Rahad y el Nilo Azul. Los Bertha, al sur del Nilo Azul. En ambos territorios se produjeron procesos de estatalización. En el caso de los Hamaj, tenemos la dinastía Abu Shok: se trata en origen de un migrante procedente del Sultanato Funj que se asienta en la localidad de Guba, se casa con una mujer local y da origen a una dinastía que gobierna la región entre mediados del siglo XIX y los años 30, aunque los últimos años como reyes vasallos del Imperio etíope (Garretson, I980). En este caso hemos podido documentar arqueológicamente los restos de la capital y se observa claramente que el monarca se dotó de un aparato material de poder característico: se construyó un palacio sobre una colina que remeda las mansiones fortificadas sudanesas y accede a bienes occidentales -desde vajilla a un automóvil (un Ford modelo T que todavía pudimos ver abandonado) (Figura 9).

En el caso de los Bertha (Triulzi I98I), el proceso de estatalización se produce también con la llegada de migrantes desde el Sultanato de Funj, entre fines del siglo XVIII e inicios del siglo XIX. Se desarrollan varias jefaturas, cada una con un jeque a la cabeza, pero durante el último cuarto del siglo XIX, la dinastía Khoyele, basada en la localidad de Asosa, se hace con el poder en todo el territorio y controla a los demás jeques. Como en el caso de Guba, el proceso de conversión en un estado propiamente dicho se frustra por la expansión del Imperio etíope. La plasmación material del poder de los Khoyele es distinta a los Abu Shok. En este caso levantan estructuras de adobe menos monumentales que el palacio de Guba y, sobre todo, una corte de justicia que es una gran cabaña de tierra, similar a las estructuras vernáculas pero de mayores dimensiones (González-Ruibal 20II). Así como Khoyele busca legitimación en el Sultanato Funj, Khoyele parece recurrir tanto a esta fuente como a la propia identidad bertha.

Hacia fines del siglo XIX, la frontera era un mosaico de comunidades con distinto grado de jerarquización y centralización. Es muy posible que de no ser por la intervención de dos potencias imperiales, Gran Bretaña y Etiopía, la tendencia hubiera sido hacia la creación de estados propiamente dichos y a la reducción de 
su número. De hecho, el caso de los estados de frontera durante el siglo XIX nos ofrece una perspectiva posible de cómo fue el proceso de creación de formaciones estatales en otros puntos del Cuerno de África a lo largo de la historia.

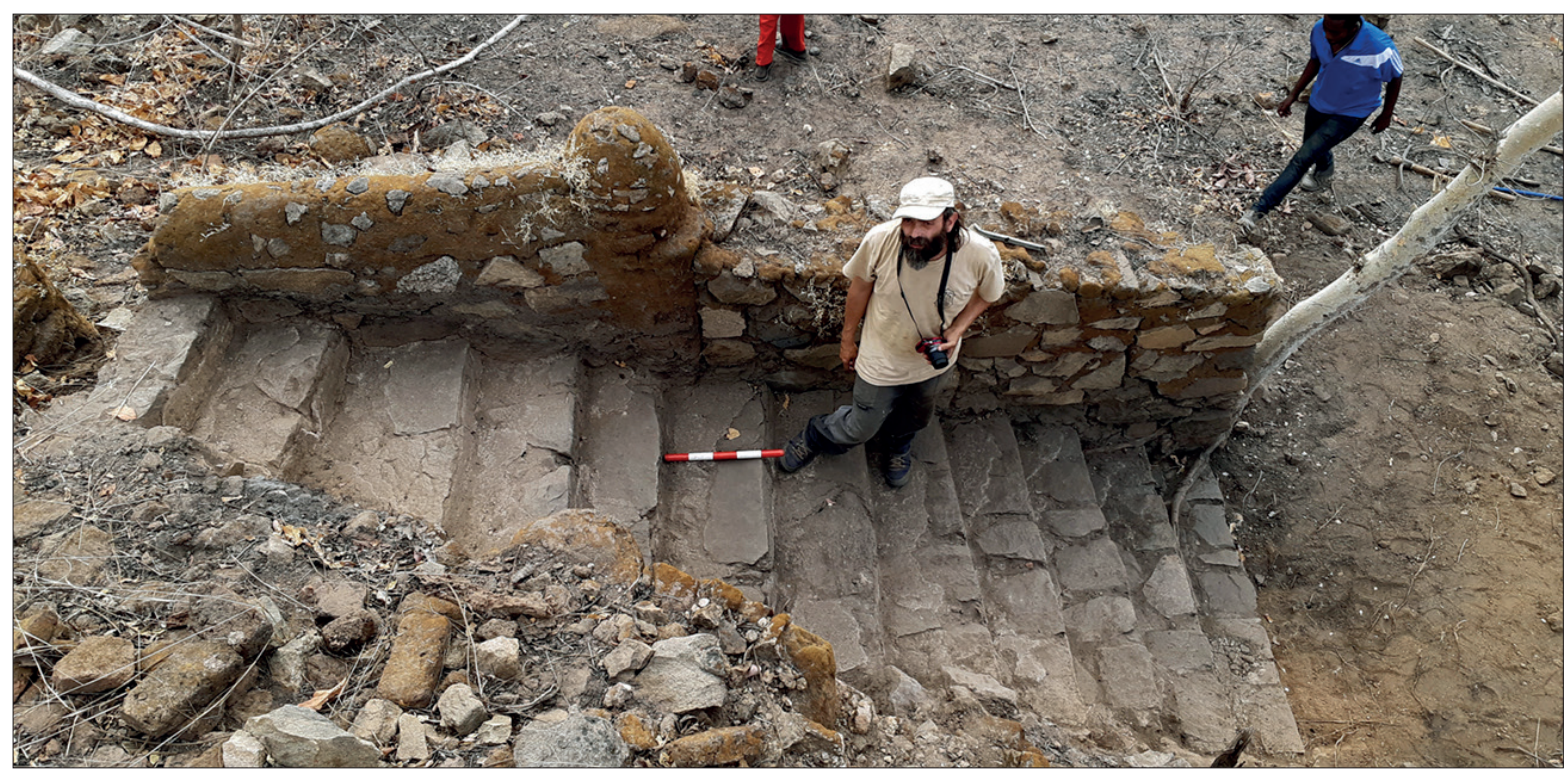

FIGURA 9. EXCAVACIÓN DE LAS ESCALERAS DE ENTRADA AL PALACIO DE HAMDAN ABU SHOK (GUBA), HACIA 1900. Foto del autor.

\section{CONCLUSIONES}

En este artículo he pasado revista a casi tres mil años de desarrollo de formaciones estatales en el Cuerno de África. Mi objetivo ha sido mostrar tanto la diversidad de formas de organización sociopolítica como la naturaleza particular de cada una de ellas. Es posible que varios modelos no encajen en las concepciones dominantes de estado, pero creo que verlos como tales nos ayuda a comprenderlos mejor (y también a comprender qué es un estado, en África y fuera de ella). En muchos casos no poseen un control efectivo del territorio, no desarrollaron escritura o son de tamaño minúsculo. Pero en todos los casos existe un monarca, una estructura jerárquica de la sociedad, un aparato de gobierno, extracción de tributos, religión institucionalizada y símbolos de poder regio. En todos los casos, pues, existe alguna de las tres formas de dominación que señalan Graeber y Wengrow: el derecho al uso de la violencia, liderazgo carismático o administración. No son diferentes, en esencia, a muchas formaciones sociopolíticas definidas como estados arcaicos. Posiblemente solo en Axum llegaron a darse los tres elementos y durante un período breve (siglos IV-VI d.C.).

Una de las características de estas formaciones estatales es la continua tensión entre fuerzas centrífugas y centrípetas. El triunfo de las fuerzas centrífugas -en forma de nómadas o jefes que se rebelan, por ejemplo- lleva al colapso de los estados y la aparición de formas menos jerarquizadas de organización social. Esto sucedió con el reino de D'MT hacia el 400 a.C., con Axum a fines del primer milenio d.C. y 
con el reino cristiano de Etiopía a fines del siglo XVIII. El conflicto que arrasa en la actualidad el norte de Etiopía y se extiende de diversos modos por el resto del país es un episodio más en esta trayectoria de tres mil años de fricción entre fuerzas centralizadoras y resistencias a la centralización. Sin embargo, como hemos podido observar a lo largo del artículo, incluso en aquellos momentos en que el estado gozó de mayor poder, como en la Etiopía cristiana en el siglo XVII o con el Sultanato de Adal en el siglo XV, jamás logró controlar de forma efectiva un territorio homogéneo con fronteras bien delimitadas. Ni lo intentó, de hecho. Estados fragmentarios, duales, no continuos, porosos o segmentarios: eso es lo que caracteriza la experiencia del estado en el Cuerno de África durante la mayor parte de su historia y, en buena medida, todavía hoy.

Sería un error, no obstante, pensar que estos reinos que no encajan en nuestro concepto de estado son privativos del Cuerno de África o de la región subsahariana. Muchos de los rasgos que caracterizan a estas formaciones sociopolíticas los encontramos en estados clásicos de época preindustrial. Los casos de estudio aquí presentados pretenden ser, también, una manera de ayudarnos a repensar los reinos e imperios que tenemos más cerca: desde el Imperio romano a los estados europeos del Antiguo Régimen.

\section{Agradecimientos}

Las investigaciones llevadas a cabo por el autor en Etiopía han sido financiadas por el Ministerio de Cultura dentro del programa de ayudas a proyectos arqueológicos en el exterior. Las investigaciones en Somalilandia por el Ministerio de Ciencia e Inmovación, dentro del programa estatal de generación de conocimiento (proyectos HAR2013-48495-C2-I-P. y (PGC2018-099932-B-loo). Agradezco a dos revisores anónimos sus valiosos comentarios que han permitido mejorar este artículo. 


\section{REFERENCIAS}

AbIR, M. 2013 [I980]: Ethiopia and the Red Sea: The Rise and Decline of the Solomonic Dynasty and Muslim European Rivalry in the Region. Routledge. Londres.

ANFrAY, F. 20I2: Matara: the archaeological investigation of a city of ancient Eritrea. Palethnologie 4:II-48.

Arthur, K. W., Stretton, S., \& Curtis, M. C. 2020: Collaborative Mapping of Sacred Forests in Southern Ethiopia: Canopies Harboring Conflict Landscapes?. African Archaeological Review 37(I): I43-I68.

Bard, K. A., Fattovich, R., Manzo, A., \& Perlingieri, C. I997. Archaeological investigations at Bieta Giyorgis (Aksum), Ethiopia: I993-I995 field seasons. Journal of Field Archaeology 24(4): 387-403.

Bowersock, G. W. 2013: The throne of Adulis: Red Sea wars on the Eve of Islam. Oxford University Press. Oxford.

Butzer, K. W. I98I: Rise and fall of Axum, Ethiopia: a geo-archaeological interpretation. American Antiquity 46(3): 47I-495.

CAsson, L. 20I2: The Periplus maris erythraei. Princeton University Press. Princeton.

Chekroun, A., \& Hirsch, B. 2020: The Sultanates of Medieval Ethiopia. In S. Kelly: A Companion to Medieval Ethiopia and Eritrea. Brill. Amsterdam: 86-II2.

ChitTick, N. I982: Mediaeval Mogadishu. Paideuma 28: 45-62.

Clastres, P. 200I. Investigaciones en antropología política. Gedisa. Barcelona.

Curtis, M. C. 2009: Relating the Ancient Ona culture to the wider northern Horn: discerning patterns and problems in the archaeology of the first millennium BC. African Archaeological Review 26(4): 327-350.

Derat, M. L. 2003 : Le domaine des rois éthiopiens, I270-I527: espace, pouvoir et monarchisme. Publications de la Sorbonne. París.

Derat, M. L., Bosc-Tiessé, C., Garric, A., Mensan, R., Fauvelle, F. X., Gleize, Y., \& Goujon, A. L. 202I : The rock-cut churches of Lalibela and the cave church of Washa Mika'el: troglodytism and the Christianisation of the Ethiopian Highlands. Antiquity 95(380): 467-486.

Desalegn Amsalu. 2016: An Ethnographic Introduction to the Kumpal Agaw. Journal of Ethiopian Studies 49: 35-56.

Donham, D. L. I980: Divine Kingship in Malle, Southwest Ethiopia. Cambridge Anthropology 6(3): $22-38$.

Evans-Pritchard, E. E. 2014 [I948]: The divine kingship of the Shilluk of the Nilotic Sudan. Cambridge University Press. Cambridge.

FAтTOVICH, R. I990: Remarks on the pre-Aksumite period in northern Ethiopia. Journal of Ethiopian Studies 23: I-33.

Fattovich, R. 2009: Reconsidering Yeha, c. 800-40o bc. African Archaeological Review, 26(4), 275-290.

FATtovich, R. 20io: The development of ancient states in the northern Horn of Africa, c. 3000 BC-AD Iooo: an archaeological outline. Journal of World Prehistory 23(3): I45-I75.

FAUvelle, F. X. 2020: Of Conversion and Conversation: Followers of Local Religions in Medieval Ethiopia. En S. Kelly (ed.): A Companion to Medieval Ethiopia and Eritrea. Brill. Amsterdam: II3-I4I.

Fauvelle-Aymar, F. X., \& Hirsch, B. (eds.) 201 : Espaces musulmans de la Corne de L'Afrique au Moyen Âge. DeBoccard. Paris. 
Fauvelle, F. X., \& Poissonnier, B. 20I6. The Shay culture of Ethiopia (tenth to fourteenth century AD):«Pagans» in the time of Christians and Muslims. African Archaeological Review 33(I): 6I-74.

Fortes, M., \& Evans-Pritchard, E. E. 2015 [1940]: African political systems. Routledge. Abingdon.

Gamst, F. C. 1969: The Qemant: a pagan-Hebraic peasantry of Ethiopia. Holt, Rinehart Winston. Londres.

Garretson, P. P. I980: Manjil Hamdan Abu Shok (1898-1938) and the administration of Gubba. En J. Tubiana (ed.): Modern Ethiopia. From the ascension of Menelik II to the present. Vth International Conference of Ethiopian Studies, Nice, 19-22 ${ }^{\text {nd }}$ December, 1977. Balkema. Rotterdam.

Garretson, P. P. I982. Frontier Feudalism in Northwest Ethiopia: Shaykh al-Imam'Abd Allah of Nuqara, I9OI-I923. The International Journal of African Historical Studies I5(2): 26I-282.

Gaudiello, M. \& Yule, P. 2017. Mifsas Bahri: a Late Aksumite frontier community in the mountains of southern Tigray. Survey, excavation and analysis, 20I3-I6. BAR International Series 2839. BAR. Oxford.

Getachew Robo Gebremariam 2021: A commentary on Gebreslassie Kiross study of social stratification and marginalization in the southern nations, nationalities and people region of Ethiopia: The case of Manjo minority groups. African Journal of History and Culture I3(I): 27-36.

GonZÁlez-Ruibal, A. 20II: Monuments of predation: Turco-Egyptian forts in western Ethiopia. En P. LANE \& K. MAcDonald. Slavery in Africa: archaeology and memory. Oxford University Press. Oxford: 25I-279.

GonZÁlez-Ruibal, A. 20I4: An archaeology of resistance: Materiality and time in an African borderland. Rowman \& Littlefield. Lanham, Maryland.

GonZÁlEZ-Ruibal, A. 2020: Colonies, missions, violence and trade: the historical archaeology of northeast Africa. En The Routledge Handbook of Global Historical Archaeology. Routledge. Abingdon: 660-680.

GonZÁlez-Ruibal, A. 2021: The cosmopolitan borderland: western Ethiopia c. AD 6ooI800. Antiquity 95(380): 530-548.

GonZÁlez-Ruibal, A., \& Falquina, Á. 20I7. In Sudan's Eastern borderland: Frontier societies of the Qwara Region (ca. AD 600-I850). Journal of African Archaeology 15(2): I73-20I.

GonZÁlLEZ-Ruibal, A., \& Ruiz-GálveZ, M. 20I6: House societies in the ancient Mediterranean (2000-500 BC). Journal of World Prehistory 29(4): 383-437.

GonZÁLEZ-RUIBAL, A., \& de Torres, J. 20I8: The fair and the sanctuary: gathering places in a nomadic landscape (Somaliland, I000-I850 AD). World Archaeology 5O(I): 23-40.

González-Ruibal, A., de Torres, J., Fernández, M. A. F., Barrio, C. M., \& de León Juberías, P. G. 202r: Asia in the Horn. The Indian Ocean trade in Somaliland. Archaeological Research in Asia 27: 100289.

Graeber, D. y Wengrow, D. 202I. The dawn of everything. A new history of humanity. Allen Lane. Nueva York.

Grottanelli, V. L. I940: Mao. Missione etnografica nel Uollega occidentale. Reale Accademia d'Italia. Roma.

Haberland, E. 1965. Untersuchungen zum äthiopischen Königtum. Franz Steiner Verlag. Wiesbaden.

HAILU ZeLEKE. 2007: Some notes on the great walls of Wolayta and Dawro. Annales d'Éthiopie 23(I): 399-4I2. 
Harrower, M. J., Dumitru, I. A., Perlingieri, C., et al. 20ig: Beta Samati: discovery and excavation of an Aksumite town. Antiquity 93(372), I534-I552.

Insoll, T., Khalaf, N., Maclean, R., Parsons-Morgan, H., Tait, N., GaAstra, J. \& Dussubieux, L. 202I: Material cosmopolitanism: the entrepot of Harlaa as an Islamic gateway to eastern Ethiopia. Antiquity 95(380): 487-507.

Japp, S., Gerlach, l., Hitgen, H., \& Schnelle, M. 20iI: Yeha and Hawelti: cultural contacts between Saba' and D 'MT-New research by the German Archaeological Institute in Ethiopia. In Proceedings of the Seminar for Arabian Studies 4I: I45-I60.

Joussaume, R. (ed.) I996. Tiya. L'Éthiopie des mégalithes. De la biface à l'art rupestre dans la Corne de l'Afrique. Chauvinois. Vienne.

Joussaume, R. 20I7: Mégalithisme dans le Chercher en Éthiopie. Addis Abeba : Centre Français des Études Éthiopiennes.

Joussaume, H., \& Joussaume, R. 1972: Anciennes villes dans le Tchercher (Harrar). In Annales d'Ethiopie 9(I): 2I-44.

Joussaume, R., Cros, J. P., \& Bernard, R. 2010: Chelba-Tutitti: site à stèles phalliques du sud de l'Éthiopie. Afrique: Archéologie \& Arts 6:, 85-1oo.

KopyTofF, I. (Ed.). I987: The African frontier: The reproduction of traditional African societies. Indiana University Press. Bloomington.

LULL, V. y Micó, R. 20II: Archaeology of the origin of the state: the theories. Oxford University Press.

McCann, J. C. 1995. People of the plow: An agricultural history of Ethiopia, I800-I990. University of Wisconsin Press. Madison.

Mclntosh, S.K., ed. 1999: Pathways to complexity in Africa. Cambridge University Press. Cambridge.

MiCHELS, J. W. 2005: Changing settlement patterns in the Aksum-Yeha region of Ethiopia: 700 $B C-A D$ 850. BAR International Series, I446. Oxford.

MIRE, S. 2015: Wagar, fertility and phallic stelae: Cushitic sky-god belief and the site of Saint Aw-BARKhadle, Somaliland. African Archaeological Review 32(I): 93-I09.

Mohammed Hassen. I990: The Oromo of Ethiopia: a history, I570-I860. Red Sea Press. Asmara.

Pankhurst, R. 1965: The Trade of the Gulf of Aden Ports of Africa in the Nineteeth and Early Twentieth Centuries. Journal of Ethiopian Studies 3(I): 36-8I.

PANkhURST, R. I977: The history of Bareya, Šanqella and other Ethiopian slaves from the borderlands of the Sudan. Sudan Notes and Records 58: I-43.

Phillipson, D. W. 2012: Foundations of an African Civilisation: Aksum \& the Northern Horn, I00o BC-I300 AD. James Currey / Addis Ababa University Press. Oxford. Addis Ababa.

RoBinson, A.E. I926. The Tekruri Sheikhs of Gallabat (SE Sudan). Journal of the Royal African Society 26(IOI): 47-53.

QuiRIN, J. I998: Caste and class in historical north-west Ethiopia: the Beta Israel (Falasha) and Kemant, 1300-1900. The Journal of African History 39(2): 195-220.

Schiettecatte, J., Prioletta, A. and Robin, C.J. 202I. Sailing to the Horn of Africa: a Sabean venture. IASA Bulletin 27: 20-2I.

SchmidT, P. R., \& CURTIS, M. C. 20or: Urban precursors in the Horn: Early $\mathrm{I}^{\text {st }}$-millennium BC communities in Eritrea. Antiquity 75(290): 849-859.

Southall, A. 1988: The segmentary state in Africa and Asia. Comparative Studies in Society and History $30(\mathrm{I}:, 52-82$.

SpaulDing, J. L. I974: The fate of Alodia. Transafrican Journal of History 4(I): 26-40. 
SteIN, G. J. I998: Heterogeneity, power, and political economy: Some current research issues in the archaeology of Old World complex societies. Journal of Archaeological Research 6(I): I-44.

Tadesse Tamrat. 1972. Church and State in Ethiopia. I270-1527. Oxford University Pres. Oxford.

Trigger, B. G. 2003. Understanding early civilizations: a comparative study. Cambridge University Press. Cambridge.

TriUlzı, A. 1981: Salt, Gold and Legitimacy: prelude to the history of a no-man's land Bela Shangul, Wallagga, Ethiopia (I80o-98). Istituto Universitario Orientale. Napole.

WARNIER, J. P. 2007: The pot-king: The body and technologies of power. Brill. Amsterdam.

WATSON, E.E. 2009: Living terraces in Ethiopia: Konso landscape, culture and development. James Currey. Oxford.

Wolf, P., \& Nowotnick, U. 20io: The Almaqah temple of Meqaber Ga 'ewa near Wuqro (Tigray, Ethiopia). Proceedings of the Seminar for Arabian Studies 40: 367-380.

Zazzaro, C. 20I3: The Ancient Red Sea port of Adulis and the Eritrean coastal region. BAR International Series 2569. BAR. Oxford. 